\title{
Effects of turning forging steels which lead to discontinuous cutting conditions
}

\author{
H K Tönshoff, Dr-Ing and W Kaestner, Dipl-Ing \\ Institute for Production Engineering and Machine Tools, University of Hannover, Germany
}

\begin{abstract}
An important component of the total production costs of forged parts are the costs for finish turning. During the last few years near-netshape technology has been advanced, so that the realizable accuracy by chipless forming has been enhanced and cutting operations are necessary at connection surfaces. This can lead to discontinuous cutting processes caused by the varying depth of cut or interrupted cut. Results obtained from turning tests with continuous cutting cannot be used as a base for the machining of those forged parts. For a reduction of production costs of near-net-shape forged parts further investigations on machinability are necessary by adapted testing methods.
\end{abstract}

\section{INTRODUCTION}

Steel is still one of the most important materials for high quality products. A growth in using improved steels with special demands on their critical levels of strength or toughness, as well as their formability and machinability, can be observed.

Production costs of forged parts mainly consist of the cost for material, for chipless forming and cutting operations. Figure 1 shows three typical drop-forged parts which are used for automobile engines or drives: steering-knuckle arm, steering swivel and riding bed. Machining costs by turning, milling and drilling are high and make $45-75$ per cent of the whole manufacturing cost depending on the particular part. It is obvious that the machinability of the workpiece has

The MS was received on 14 May 1990 and was accepted for publication on 25 January 1991 . great potential for possible cost reduction, this means decreasing wear and preventing the tool from early fracture. However, machining forged parts leads to difficult cutting conditions with changing depth of cut or interrupted cut. These heavy conditions cannot be compared with results obtained by continuous turning processes; therefore, an adapted testing method is necessary to simulate the changing depth of cut and interrupted cut when turning.

In this paper some testing methods and results are reviewed that are achieved by turning a $\mathrm{Ck} 45$ steel (BS 060 A 47) with a higher sulphur content of 0.056 per cent and controlled cooling from the forging temperature.

\section{INFLUENCES ON THE MACHINABILITY OF FORGED STEELS}

Regarding the whole production process of forging, there are several factors that influence machinability:

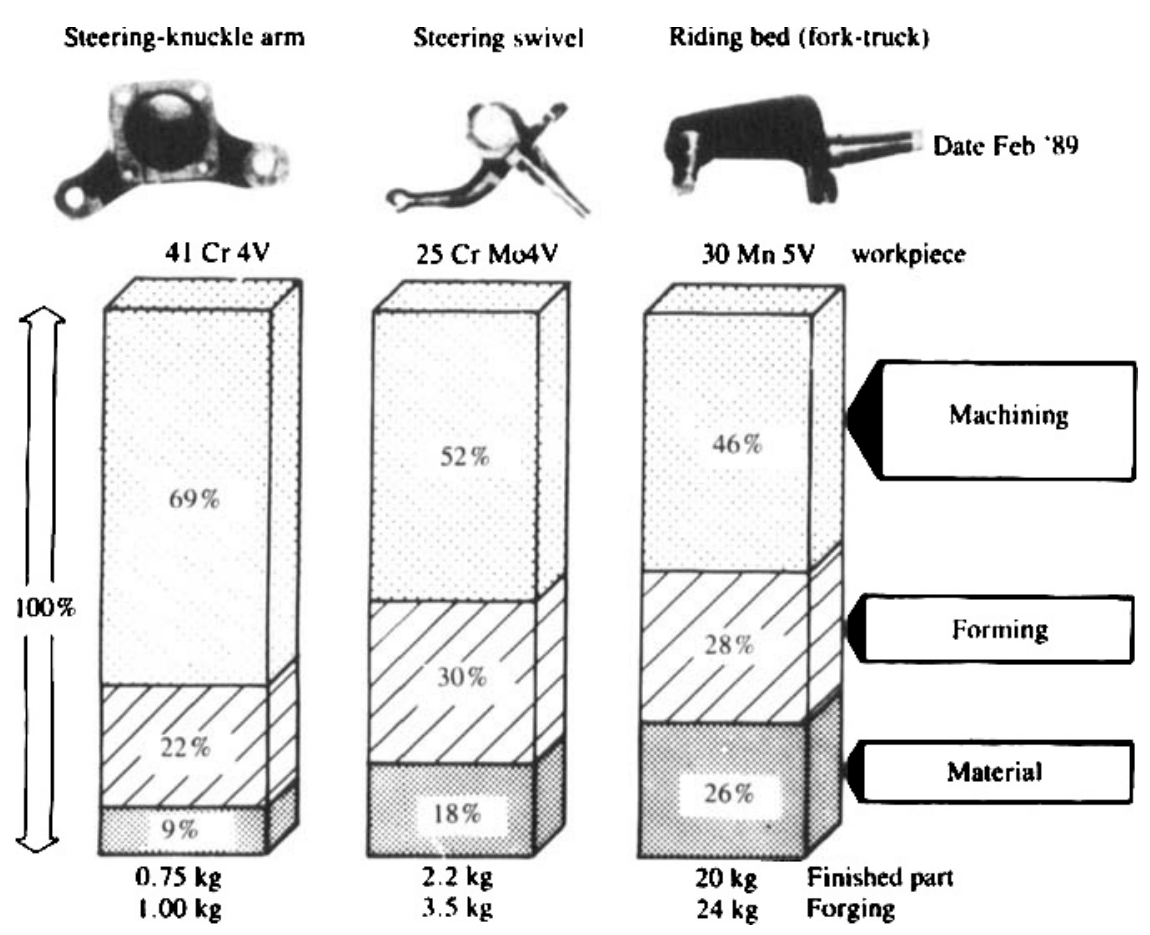

Fig. 1 Production costs of typical drop-forged parts 


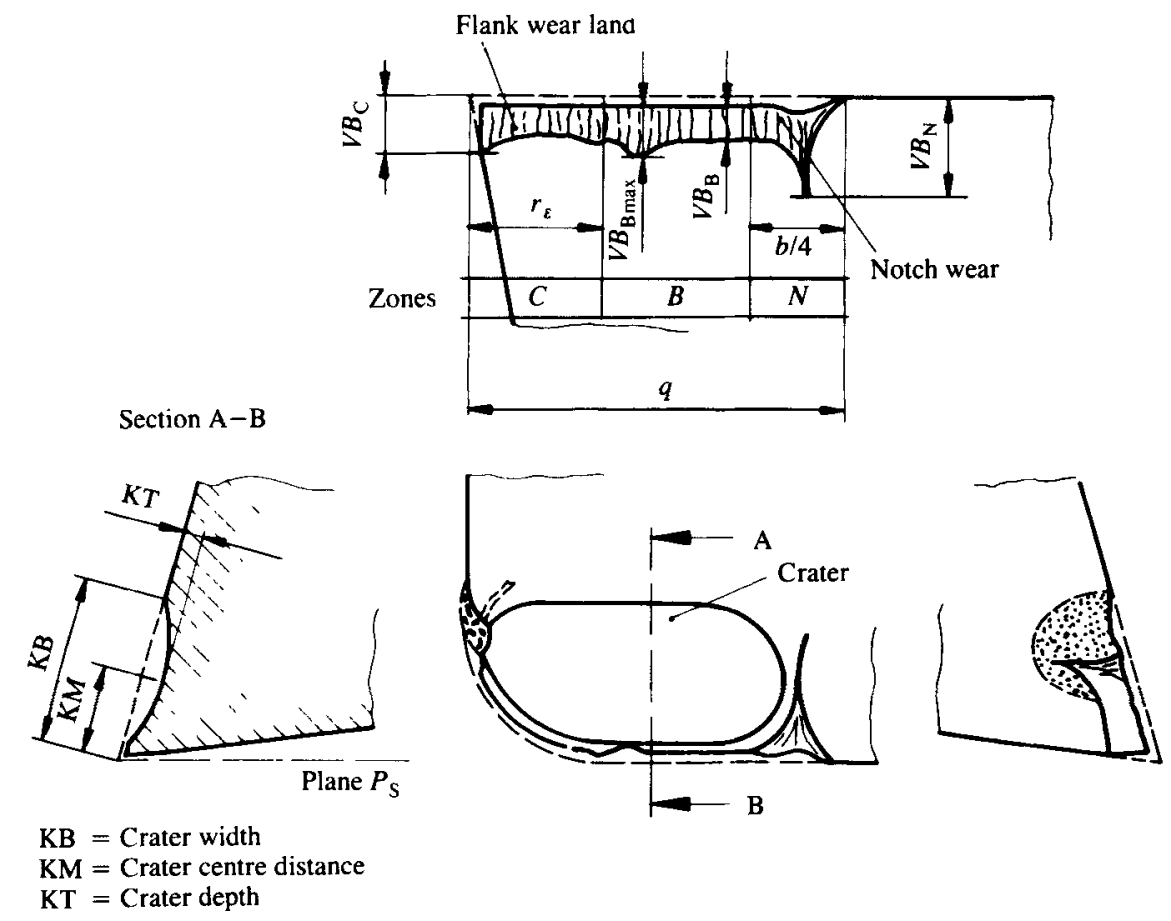

Fig. 2 Types of wear on turning tools (10)

the control of the melting process, the chemical treatment and deoxidation of the steel, the control of the deformation process and the heat treatment.

Among the chemical treatments, the sulphur content is one important method of increasing machinability.

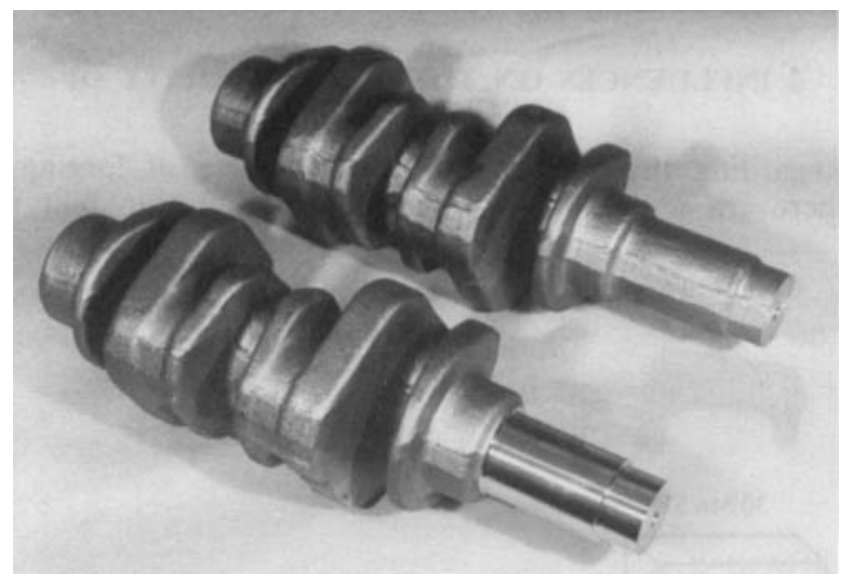

Fig. 3 Crankshaft before and after turning operations

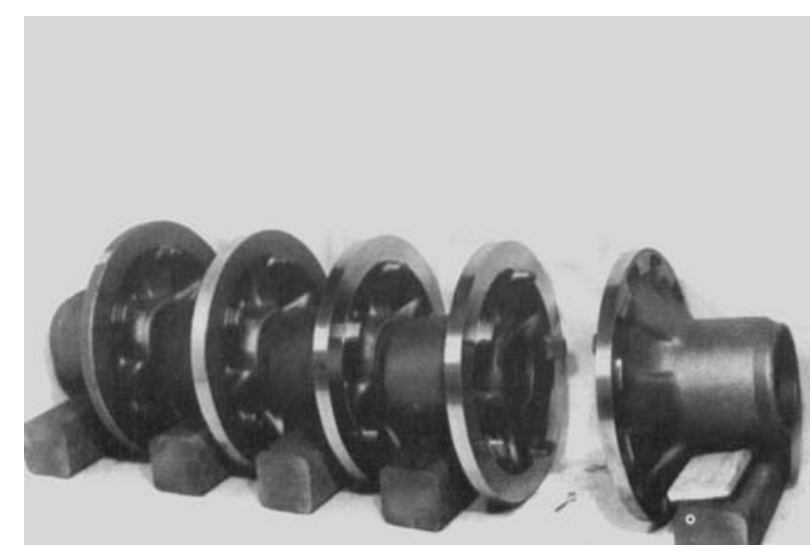

Fig. 4 Wheelhub before and after turning operations
The positive effect follows from the creation of $\mathrm{MnS}$, which leads to higher ductility and better friction conditions between chip and tool (1). The addition of special deoxidation agents such as $\mathrm{CaS}$ or FeS lead to a wearprotective layer when using carbide or ceramic cutting tools (2-5). The aim of the process development in heat treatment leads to simplified heat treatment methods like fully heat treating or controlled cooling, especially for new micro-alloyed steels with vanadium, where a cooling rate must be chosen which creates a ferriticpearlitic microstructure for good machinability. This socalled BY treatment is a controlled cooling from the forging temperature (6-8).

The different possibilities for further development of engineering steels described above may lead to new workpiece materials in many cases, which in interacting with an appropriate tool material, result in better machinability (9).

A further influence on the machinability of forged engineering steels originates from the varying material quality and the changing workpiece geometry at the outer surface. The finishing operation by turning, mainly the tool wear, is strongly affected by workpiece deviations. Figure 2 shows some typical types of wear at a turning tool according to ISO $3685(\mathbf{1 0})$. The main problems when machining the outer surface of a forged workpiece are caused by changing the depth of cut (see Figs. 3,4$)$ and interrupted cut (Fig. 4). In a running production line these problems compel a reduction of feedrate and cutting speed, so that the main machining time is prolonged and the manufacturing costs, that directly depend on the cutting time, increase.

\section{CHANGING DEPTH OF CUT}

Lange and Kemna (11) realized several years ago that the specific geometrical and material properties of forged parts cause difficulties in machining processes. A list of mistakes which can be made during the forging 
process itemizes distinct cases and provides suggestions for overcoming the problems. Workpiece geometry is an important factor according to Lange $(12,13)$. Residual flash leads to impact loads on the tool which is a probable reason for tool breakage. He therefore recommends an adaptation of the direction of the workpiece revolution to the direction of residual flash to avoid a sudden increase of the depth of cut during the turning process. Geometrical deviations additionally lead to eccentricity and non-circular machined surfaces. Patzke and Tönshoff et al. $(14,15)$ showed that geometrical deviations cause higher tool wear during turning due to the changing depth of cut. Possible reasons can be found in adhesion- and exfoliation-mechanisms, which become more important during discontinuous cutting in comparison to continuous cutting.

To investigate the influence of geometrical deviations of forged parts on the machinability of different workpiece shapes, variations were simulated on rolled shafts with a diameter of $80 \mathrm{~mm}$ (Fig. 5). Before beginning the machinability tests, the geometrical deviations were prepared by milling. Eccentricity and outside slice showed good accordance with the geometry of forged parts. Because of the high costs of preparing workpieces for residual flash and mismatch, no exact imitation of forged parts could be realized. However, the conditions for engagement and disengagement of the tool were in accordance with real parts.

Machining the workable material Ck $45+$ S BY (BS 060 A 47 with higher sulphur content, which was controlled cooled) with $\mathrm{TiC}$-coated carbide of ISO grade P25 gave the following results. In comparison with continuous cutting, the carbide tool used showed a charac-

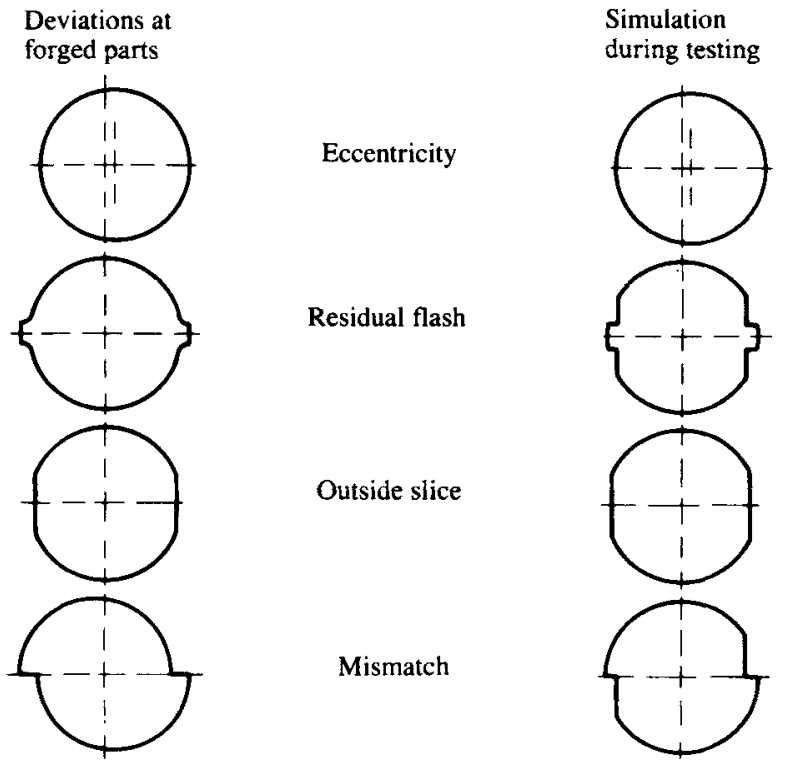

Fig. 5 Simulation of different kinds of deviation at cylindric forged parts

teristic wear type in alternating depth of cut. This wear type occurred after a very short cutting time, and was mainly found at the tool surface. Figure 6 shows scanning electron micrographs of worn carbide tools, which were used for turning the workpieces described above. The depth of cut varied between 1 and $3 \mathrm{~mm}$. It is obvious that differences in the type and amount of wear occurred depending on the alteration of the depth of cut. Only within the first millimetres-from the tool

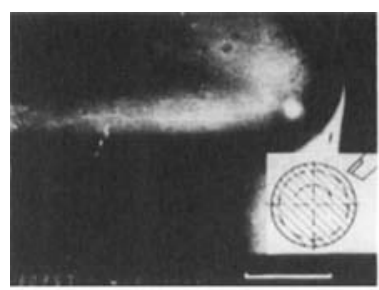

Continusus cut

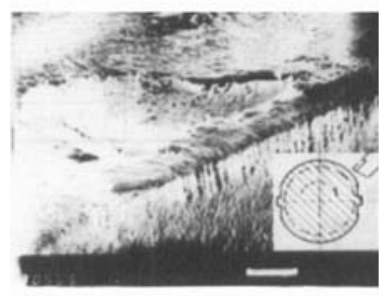

Residual llash

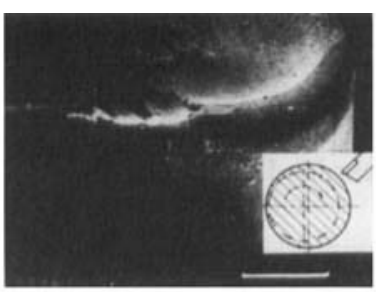

Ecentricity

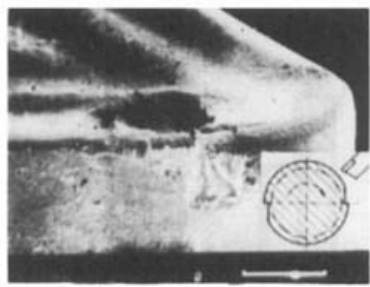

Incoming mismatch

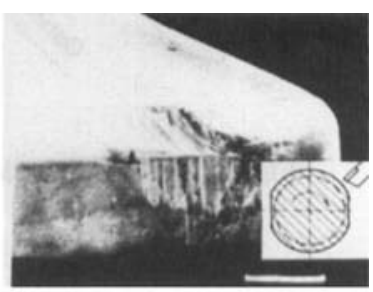

Outside slice

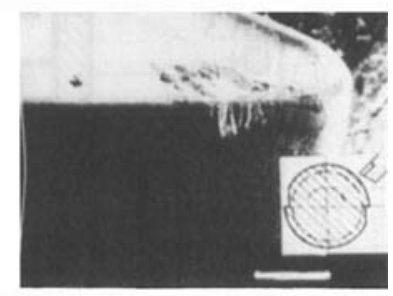

Oulgting mismatch

$$
\begin{array}{ll}
\text { Workpiece material } & \mathrm{Ck} 45+\mathrm{S} \mathrm{BY} \\
\text { Cutting speed } & \mathrm{t}_{\mathrm{c}}=200 \mathrm{~m} / \mathrm{min} \\
\text { Feed rate } & f=0.33 \mathrm{~mm} \\
\text { Depth of cut } & a_{\mathrm{p}}=1-3 \mathrm{~mm} \\
\text { Cutting time } & t_{\mathrm{c}}=10 \mathrm{~min} \\
\text { Tool material } & \mathrm{HM} 25 \mathrm{C}
\end{array}
$$

\begin{tabular}{|c|c|c|c|c|c|}
\hline$\alpha$ & $y$ & $\lambda$ & $\varepsilon$ & $x$ & $r_{\varepsilon}$ \\
\hline $6^{\circ}$ & $9^{\circ}$ & $6^{\circ}$ & $60^{\circ}$ & $93^{\circ}$ & $1.2 \mathrm{~mm}$ \\
\hline
\end{tabular}

Fig. 6 Scanning electron micrographs of worn carbide tools in dependence on the kind of deviation 
radius-did the usual wear occur, comparable with continuous cutting processes. In the region of discontinuous cut the wear grew rapidly and after a few minutes the coating at the tool face spalls off. Then the crater wear grew until it reached the cutting edge and a rapid flank wear increase followed.

The influence of the value of changing depth of cut was examined by different deviations of $1,1.5$ and 2 $\mathrm{mm}$. A summary of the appearing maximum width of flank wear land $V B_{\mathrm{Bmax}}$ and crater ratio $K$ (this is the crater depth $K T$ devided by crater centre distance $K M$ ) is shown in Fig. 7 and 8. The cutting time was $7.5 \mathrm{~min}$. It can be seen that the type and the amount of changing depth of cut did not strongly affect the flank wear, as long as there was no damage to the tool edge. Crater wear, however, was significantly accelerated by changing the depth of cut in comparison to continuous cutting. The wear directly depends on the kind of changing depth of cut as well as the value of deviation
$(1,1.5,2 \mathrm{~mm})$. The crater ratio increased particularly in turning the outside slice, residual flash and incoming mismatch. A doubled value of deviation from 1 to $2 \mathrm{~mm}$ led to a 100 per cent higher crater ratio.

The observed wear at the cutting tool when turning with changing depth of cut can be traced back to the mechnisms adhesion as well as mechanical and thermomechanical surface fatigue.

\section{INTERRUPTED CUT DURING TURNING}

Machining operations in interrupted turning processes generally encompass different conditions in comparison to those of continuous turning. These are essentially characterized by:

(a) tool entry into the workpiece;

(b) tool exit from the workpiece;

(c) cyclic thermal and mechanical loading and unloading.

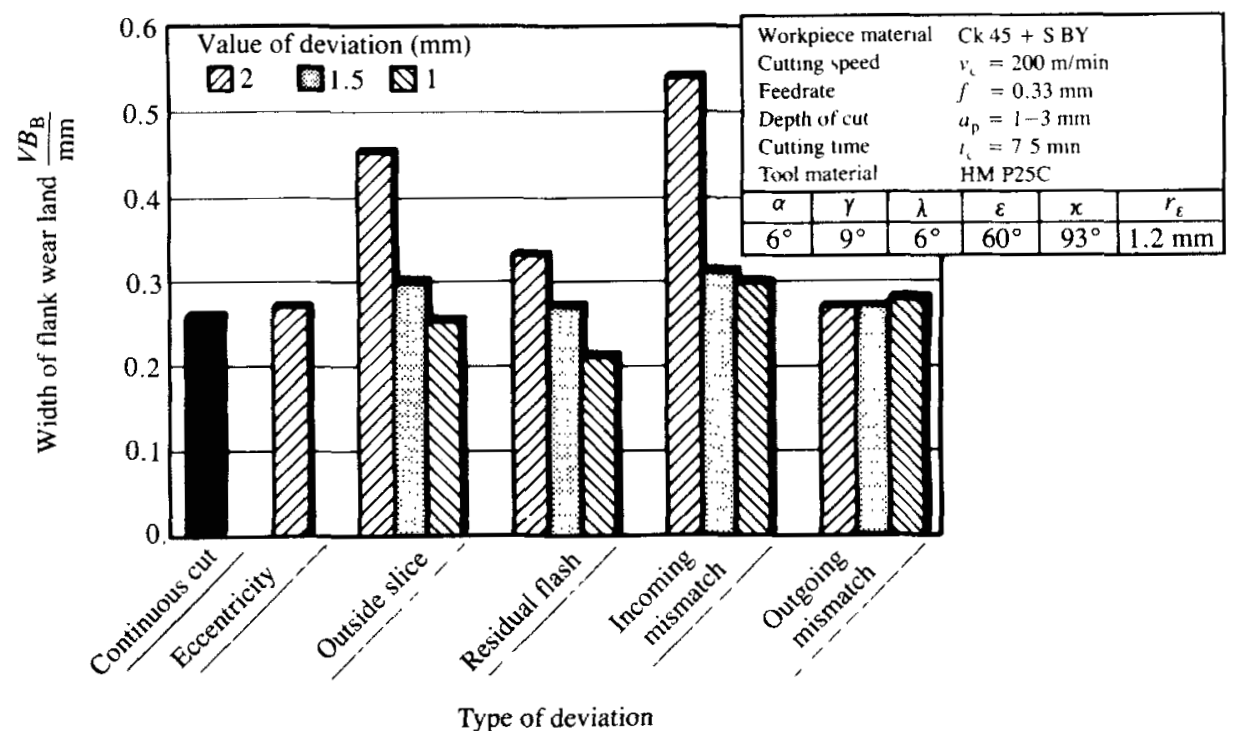

Fig. 7 Width of flank wear land after machining shafts with different deviations

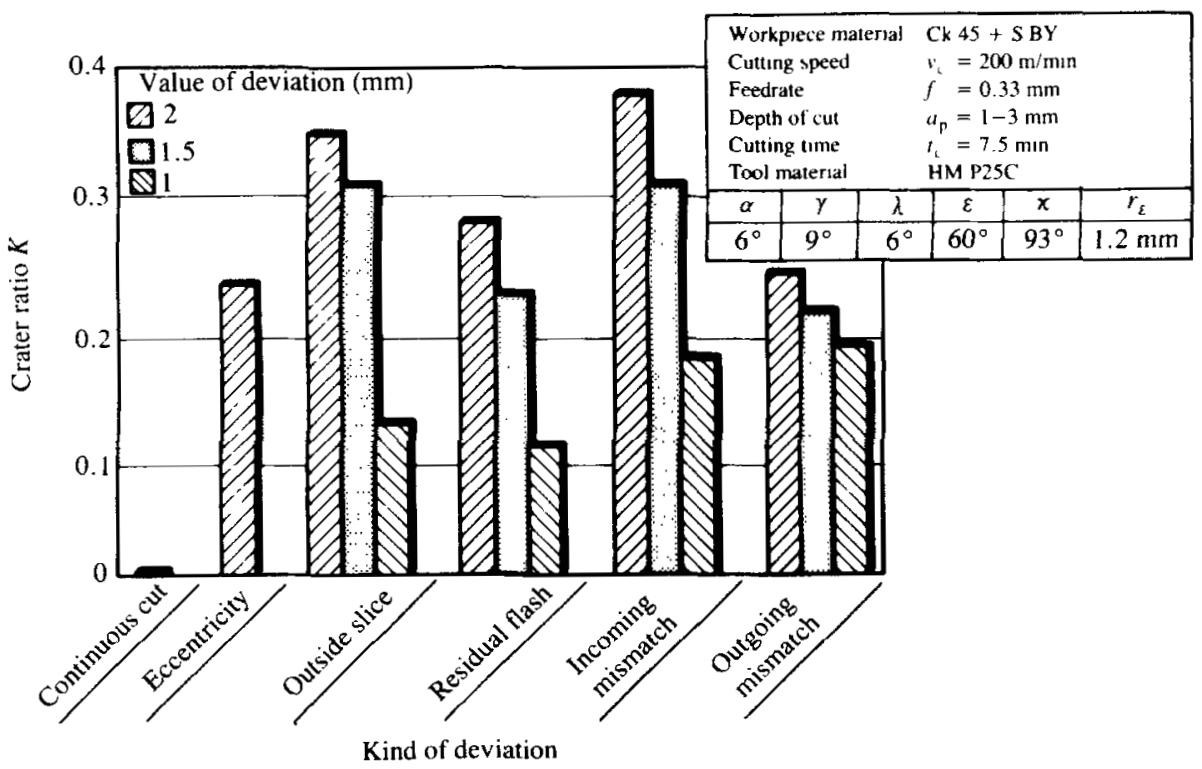

Fig. 8 Crater ration after machining shafts with different deviations 
Examination of the work from various authors (16-21) shows the connection between tool life entry/ exit conditions for milling operations. For a long time there was no extensive research of the cyclic change of the tool temperature load, although Okushima and Hoshi (22) theoretically proved the influence of the cutting-time ratio on the temperature distribution inside a carbide tool using a single-dimensional model. Yellowly and Barrow (23) made an analysis of the thermal strain produced in the peripheral milling process and found that the range of thermal strain and also the number of cycles of thermal strain have considerable influence on tooth life. Orady and Tlusty (24) stated, when using a high-speed steel milling cutter, that the ranges of temperature are independent of the ratio of in-cut/out-of-cut periods. But it was only proved at two contact rates $H_{\mathrm{E}}=25$ per cent and $H_{\mathrm{E}}=50$ per cent. Experimental investigations when milling with oxide ceramic lead to cutting temperatures between $650^{\circ} \mathrm{C}$ and $730^{\circ} \mathrm{C}$ before cooling down to ambient temperature (25).

The interrupted cut during turning was investigated only with regard to a sudden tool breakage to test the toughness of the tool material (26-29), but the influence of different contact rates of workpiece material to be cut during one revolution at ambient were not examined. The first experiments changing the contact rate by Tönshoff, Kaestner and Patzke (30, 31) show the influence on tool life with a maximum tool life existing in the region of a contact rate of $H_{\mathrm{E}}=20-40$ per cent.

The experimental results described in the following were realized with an especially constructed device shown in Fig. 9. It allows variation of contact rate $H_{\mathrm{E}}$ over a wide range by clamping different numbers of workpieces into the testing device. The characteristic quantity of the cutting edge contact rate, $H_{\mathrm{E}}$, is worked out during one revolution by

$$
\begin{aligned}
H_{\mathrm{E}}= & \frac{\sum l_{\mathrm{ci}}}{\sum l_{\mathrm{ci}}+\sum l_{\mathrm{oi}}} \times 100 \%=\frac{\sum t_{\mathrm{ci}}}{\sum t_{\mathrm{ci}}+\sum t_{0 \mathrm{i}}} \\
& \times 100 \%=\frac{t_{\mathrm{ci}}}{t_{\mathrm{pi}}} 100 \%
\end{aligned}
$$

where $t_{\mathrm{ci}}$ is the material cutting time, $t_{0 \mathrm{i}}$ is the air cutting time and $t_{\mathrm{pi}}$ the process time.

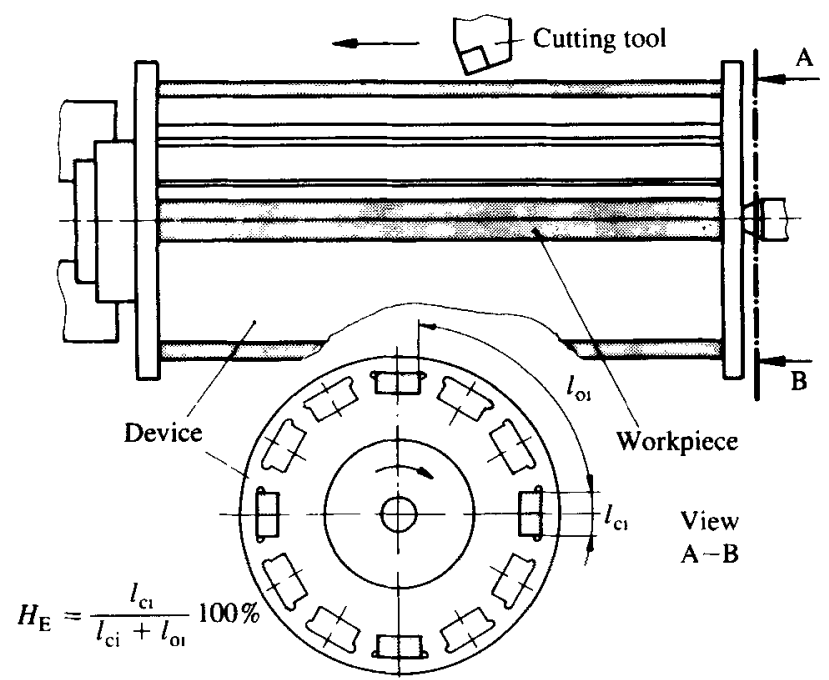

Fig. 9 Experimental device for interrupted turning
The workpiece material machined was a $\mathrm{Ck} 45+\mathrm{S}$ BY (BS 060 A 47 with higher sulphur content). The main pearlite structure is surrounded with ferrite (15-20 per cent), which causes a relative high hardness of 214 HB. The tool material was an uncoated carbide of ISO grade P25 and the tests were carried out with constant depth of cut $\left(a_{\mathrm{p}}=2.5 \mathrm{~mm}\right)$ and variable feed rate $(f=0.16-0.315 \mathrm{~mm})$ and contact rate $\left(H_{\mathrm{E}}=5-65\right.$ per cent).

The critical points of mechanical load are the tool entry and exit, where forces increase or decrease rapidly. The mechanical load at the cutting edge depends in a specific way on the initial contact between tool and workpiece. Figure 10 shows the contact parallelogram STUV after Kronenberg (32). At each corner of the parallelogram an initial contact is possible and depends on the combination of workpiece and tool geometry. Linear contact on one connection line of the four corners is also possible, but seldomly occurs. The worst impact type is S-contact, because the whole mechanical load is concentrated on the most sensitive part of a tool-the cutting edge. To prevent this undesirable situation, a tool geometry was chosen that led to the more stable T-contact. With increasing feedrate the force components exerted by the tool increase and challenge the toughness of the tool material. The dependence between tool wear and the cutting time is shown in Fig. 11. With increasing feedrate early tool breakage occurred above a distinct value. The toughness of the tool material was insufficient to withstand the rapidly rising forces.

Mechanical loads are not the only reason for tool failure. Together with the mechanical load, thermal loads with alternating heating and cooling cycles occur. After a short machining time these loads can lead to thermally induced cracks on the tool surface perpendicular to the tool face which additionally weaken the tool (Fig. 12). Although the width of flank wear land $V B_{\mathrm{B}}$ is not too large and is far from a critical value (about $80-100 \mu \mathrm{m}$ ), the combination of thermal and mechanical loads quickly leads to tool failure during machining.

Heating and cooling cycles during turning with interrupted cutting affect the tool life of an uncoated carbide

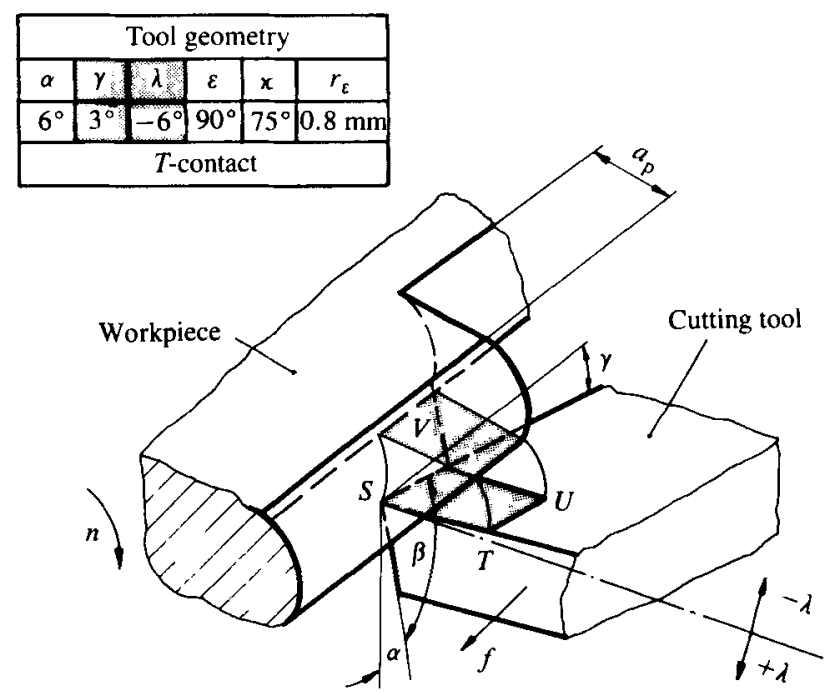

Fig. 10 Contact zone between workpiece and tool 


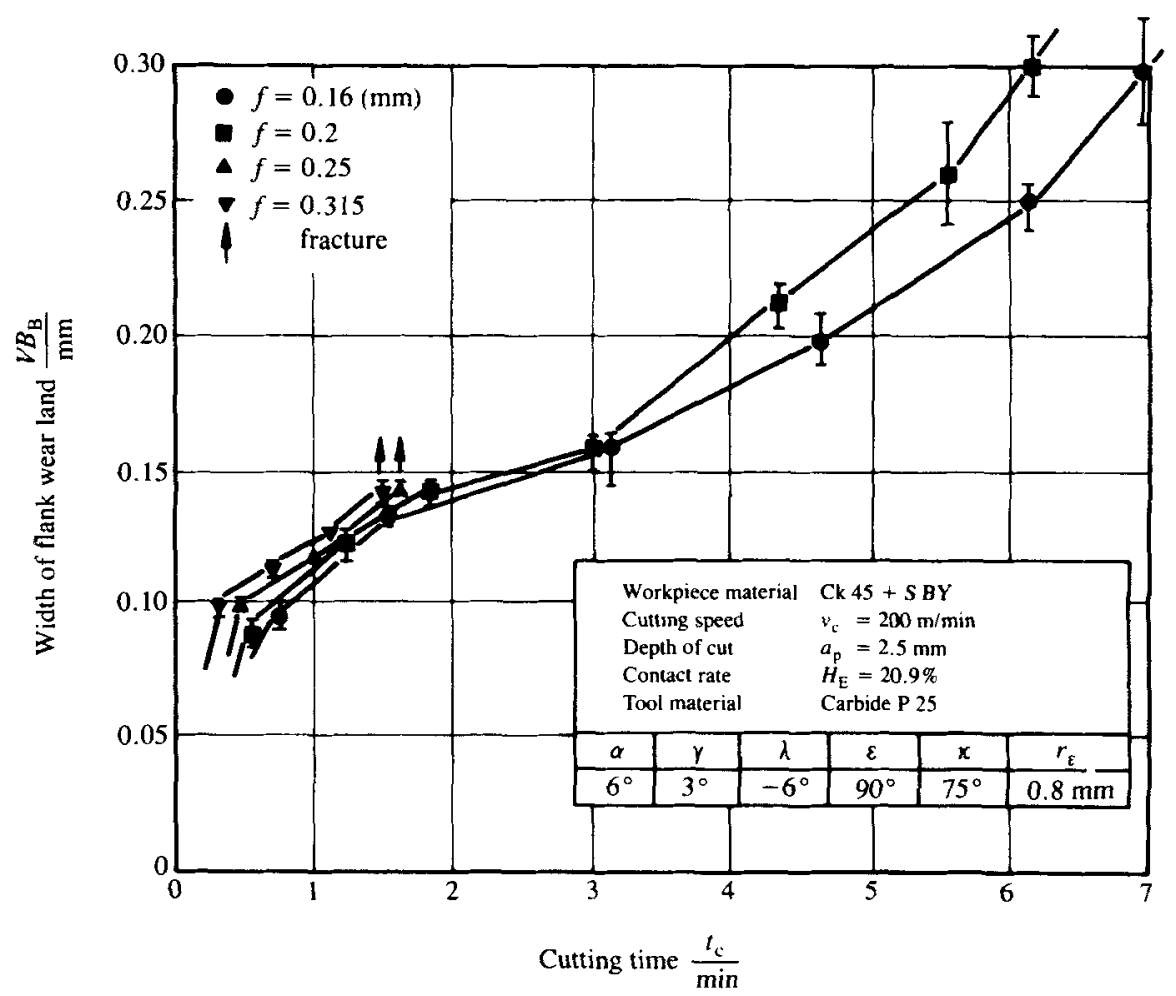

Fig. 11 Tool wear in dependence on cutting time and feedrate

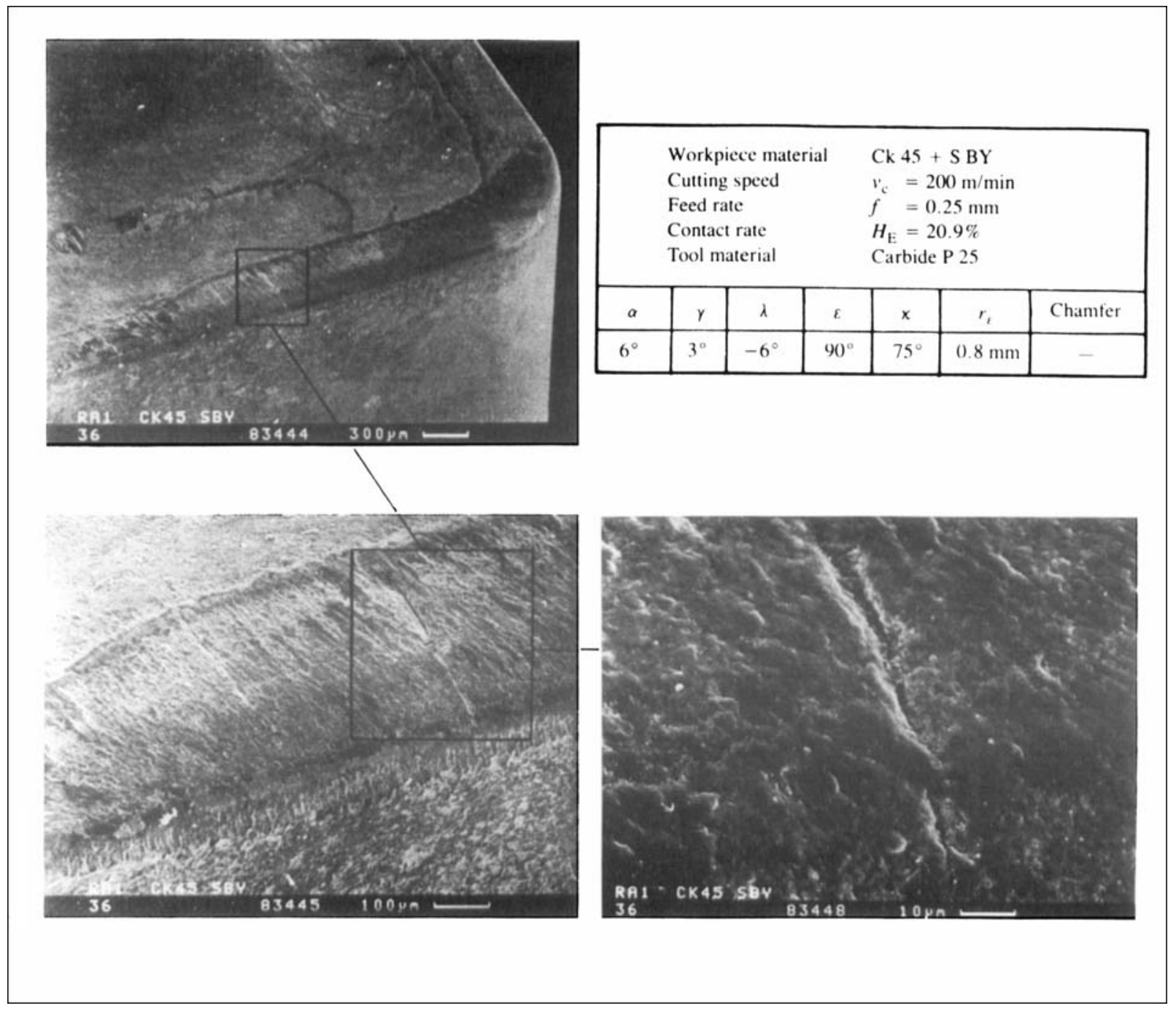

Fig. 12 Scanning electron micrographs showing crack formation during interrupted turning 
in a specific way. The simulation is realized by clamping different numbers of plates into the testing device. With a cutting speed of $200 \mathrm{~m} / \mathrm{min}$ the following times during one cycle can be realized:

\begin{tabular}{cccc}
\hline $\begin{array}{c}\text { Number of } \\
\text { plates }\end{array}$ & $\begin{array}{c}\text { Contact rate, } H_{\mathrm{E}} \\
\%\end{array}$ & $\begin{array}{c}\text { Heating time, } t_{\mathrm{ci}} \\
\mathrm{ms}\end{array}$ & $\begin{array}{c}\text { Cooling time, } t_{\mathrm{ci}} \\
\mathrm{ms}\end{array}$ \\
\hline 1 & 5 & 15 & 285 \\
2 & 11 & 15 & 135 \\
3 & 16 & 15 & 85 \\
4 & 21 & 15 & 50 \\
6 & 31 & 15 & 35 \\
12 & 62 & 15 & 10 \\
\hline
\end{tabular}

Figure 13 shows the results of such cutting tests on a normalized $\mathrm{Ck} 45 \mathrm{~N}$. With increased cutting edge contact rate $H_{\mathrm{E}}$, the tool life rises to a maximum, to fall to lower values with a further increase of $H_{\mathrm{E}}$. Scanning electron micrographs give clues about the existing loads. At a low contact rate the cooling time was long in comparison to the heating time, so that the temperature change on the tool surface was very intense, which led to thermal cracks on the tool surface. These were long, narrow and deep, and weakened the cutting tool significantly. With increased contact rate the cooling time decreased until the heating time was longer than the cooling time $\left(t_{\mathrm{ci}}=15\right.$ and $\left.10 \mathrm{~ms}\right)$. This may lead to a relatively low temperature change cycle and cause less cracks or no cracks at all on the tool surface*.

\section{CONCLUSIONS}

This paper gives results about the machinability of forged steels in discontinuous cutting processes. The main problems were caused by changing the depth of cut or interrupted cut, leading to heavy cutting conditions. The tool material had to withstand extreme changes in mechanical and thermal loads. Experiments were carried out by turning a Ck 45 steel (BS 060 A 47) with higher sulphur content which was controlled cooled from the forging temperature. Geometrical workpiece deviations led to higher tool wear in comparison to continuous turning processes. During interrupted turning thermally induced cracks were formed on the tool surface, which weakened the tool. These occurred only in the case of the short cutting edge contact rate, when longer cooling times of the tool surface arose. Therefore it was necessary to avoid short contacts between tool and workpiece followed by longer cooling times, where the significant roll of cooling for the tool became evident. If this was not possible one

- Latest investigations about the real temperature at the tool surface of a carbide show that the temperature cycle is higher at low contact rate $\left(\Delta \theta=500^{\circ} \mathrm{C}\right.$ ) and lower at greater contact rate (up to $\Delta \theta=400^{\circ} \mathrm{C}$ ). The lowest time before a re-entry into the workpiece was measured with $\theta=76^{\circ} \mathrm{C}$ at $H_{\mathrm{E}}=$ $5 \%$ and $\theta=410^{\circ} \mathrm{C}$ at $H_{\mathrm{E}}=62 \%$

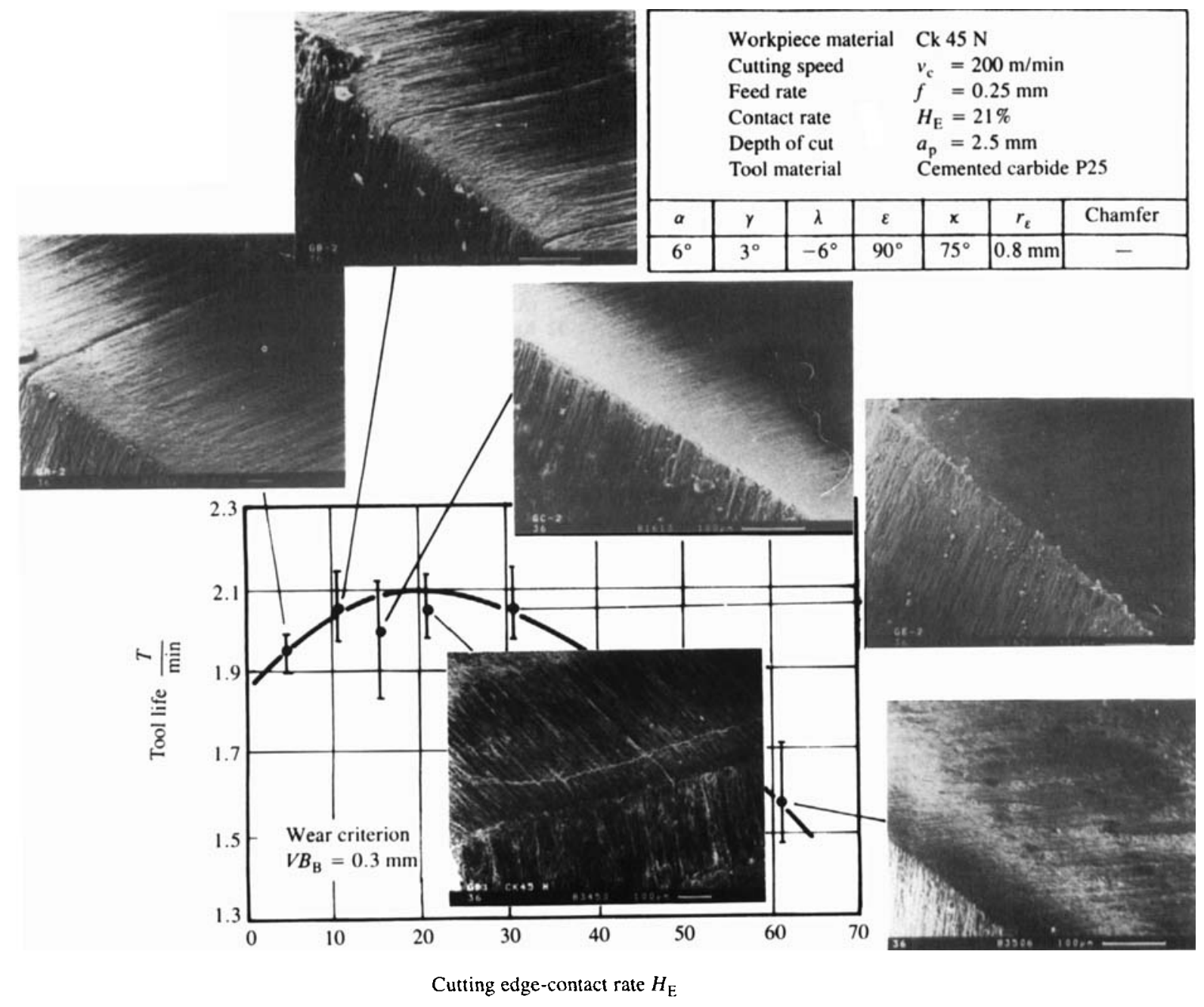

Fig. 13 Tool life and scanning electron micrographs showing dependence on contact rate 
had to observe the tool insert carefully to judge the time when the tool was weakened so much that sudden failure occurred.

\section{REFERENCES}

1 Engineer, S., Huchtemann, B. and Schüler, V. An investigation of the effect of sulphur, tellurium and calcium on the machinability and the technological properties of engineering steels. First International Conference on the Behaviour of materials in machining, Stratford-upon-Avon, 8-10 November, 1988 (Institute of Metals, London).

2 Palmai, Z. The effect of deoxidation of steel on machinability. Wear, 1976, 38, 1-16.

3 Apple, C. A. The relationship between inclusions and the machinability of steel. Thirty-first Mechanical working and steel Conference Proceedings, Chicago, USA, 22 October 1989 (American International Manufacturing Engineering).

4 Pöntinen, H. and Paju, M. Effect of layer formation on the machinability of steels. Proceedings International Conference and Workshop on Factors influencing machining and their control, Cincinnati, USA, 12-14 September 1989, (Ed) H. E. Finn (ASM International, Ohio, USA).

5 Tönshoff, H. K., Kaestner, W. and Schnadt, R. Metallurgische Auswirkungen der Calciumbehandlung von Stahlschemlzen auf die Bearbeitbarkeit. Stahl und Eisen, 1989, 109, (13), 651-660.

6 Engineer, S., Huchtemann, B. and Schüler, N. A review of the development and application of microalloyed medium-carbon steels. Proceedings of Conference on Fundamentals of microalloying forging steels (Eds G. Krauss and S. K. Banjerji), Warrendale, USA, 1987.

7 Naylor, D. J. Review of international activity on microalloyed engineering steels. Ironmaking and Steelmaking, 1989, 16, (4), 246252.

8 Cristinacce, M. and James, D. E. The development of microalloy steels at United Engineering Steels. ECSC sponsored information day on microalloyed engineering steels, Düsseldorf, 30 June 1988.

9 Naylor, D. J. The future for engineering steels. Ironmaking and Steelmaking, 1990, 17 (1), 17-25.

10 Naylor, D. J. Tool-life testing with single point turning tools. ISO 3685-1977 (E).

11 Lange, K. and Kemna, H. K. Probleme beim Vorbereiten und Spannen von Ge senkschmiedestücken zum Abspanen. Werkstattechnik und Maschinenbau, 1956, 45 (9), 434-442.

12 Lange, $K$. Die Arbeitsgenauigkeit beim Gesenkschmieden. Dr-Ing dissertation, TH Hannover 1953.

13 Lange, $K$. Cost minimization in small quantity production of stepped shafts by combined NC-radial forging and NC-turning. Ann. CIRP 1985, 34 (2), 549-555.

14 Patzke, M. Einfluß der Randzone auf die Zerspanbarkeit von Schmiedeteilen. Dr-Ing dissertation, Universität Hannover, 1987.
15 Tönshof, H. K. and Stanske, C. H. Material aspects in machining of forged parts. ASM International Conference, New Orleans, USA, 1985 (ASM International, Ohio, USA).

16 Lehwald, W. Prüfung von Hartmetallen im Hinblick auf die Schneidenbeanspruchung bei unterbrochenem Schnitt. Dr-Ing Dissertation, RWTH Aachen, 1962.

17 Beckhaus, H. EinfluB der Kontaktbedingungen auf das Standzeitverhalten von Fräswerkzeugen. Dr-Ing Dissertation, RWTH Aachen, 1969.

18 Philip, P. K. Tool wear and tool life in intermittent cutting of hardened steel using conventional hardmetal inserts. Int. J. Mach. Tool Des. Res., 1978, 18, 19-28.

19 Pekelharing, A. J. The exit failure in interrupted cutting. Ann. CIRP 1978, 27 (1), 5-10.

20 Pekelharing, A. J. The exit failure of cemented carbide face milling cutters. Ann. CIRP 1984, 33 (1), 47-50.

21 Rottberg, J., Lenz, E. and Braun, S. Mechanical signature analysis in interrupted cutting. Ann. CIRP 1987, 36 (1), 249-252.

22 Okushima, K. and Hoshi, T. Internal temperature distribution of the carbide fly cutting tool. Bull. Japan. Soc. Tech. Engrs, 1967, 10 (39), 566-573.

23 Yellowly, F. and Barrows, G. The influence of thermal cycling on tool life in peripheral milling. Int. J. Mach. Tool Des. Res. 1976, 16, 1-12.

24 Orady, E. and Tlusty, J. Effect of thermal cycling on tool wear in milling. North American Manuf. Research Conference Proceedings. University Park, PA, USA, 19-22 May, 1981.

25 Tönshoff, H. K. and Denkena, B. Wear of ceramic tools in milling. STLE Annual Meeting, Denver, USA, 7-10 May, 1990, to be published in Trans. $A S L E$ ).

26 Bhatia, S. M., Pandey, P. C. and Shan, H. S. Thermal cracking of carbide tools during intermittent cutting. Wear, 1978, 51, 201-211.

27 Asa, T., Nakatami, S. and Harra, A. Study of the early fracture of carbide tools for steel cutting (First report). Bull. Japan Soc. Prec. Engng, 1980, 14 (1), 19--24.

28 Negishi, H., Aoki, K. and Sata, T. Study on tool failure of carbide tools in interrupted turning. Ann. CIRP, 1980, 29 (1), 57-60.

29 Kunz, H. and König, W. Cutting materials, classification and standardization. Ann. CIRP, 1987, 36 (2), 531-535.

30 Tonshoff, H. K., Kaestner, W. and Patzke, M. Machinability of steel in discontinuous turning processes. First International Conference on the Behaviour of materials in machining. Stratford-uponAvon, 8-10 November, 1988.

31 Tönshoff, H. K. and Kaestner, W. Machinability of steel forgings and their economic production. Proceedings International Conference and Workshop on Factors influencing machining and their control, Cincinnati, USA, 12-14 September 1989 (Ed. H. E. Finn) (ASM International, Ohio, USA).

32 Kronenberg, M. Analysis of initial contact of milling cutter and work in relation to tool life. Trans. ASME, April 1946, 217-228. 